\title{
KOMUNIKASI TRANSEDENTAL JAMAAH GERAK BATIN DI DESA GLAGAHSARI DENGAN PENDEKATAN SYMBOLIC INTERACTION THEORY
}

\author{
Robbi Hidayat 1 , Nurma Yuwita'), Gatut Setiadi ${ }^{\text {3) }}$ \\ 1), 2)Universitas Yudharta Pasuruan, 2)IAI Sunan Kalijogo Malang \\ 1)robbihidayat15@gmail.com, ${ }^{2}$ nurma@yudharta.ac.id, ${ }^{3)}$ gatutsetiadi@iaiskjmalang.ac.id
}

\begin{abstract}
Abstrak : Gerak batin merupakan salah satu jamaah pengajian muslimah tertua dibawah naungan NU Kabupaten Pasuruan. Dalam prosesnya, terjadi perubahan makna dan tujuan dari kegiatannya. Penelitian ini menggunakan metodologi kualitatif deskriptif. Metode dalam pengumpulan data yaitu wawancara terstruktur. Hati, nafsu dan jiwa merupakan satu kesatuan yang tidak dapat dipisahkan satu sama lain. Hati mewadahi nafsu dan jiwa yang berisikan dorongan untuk melakukan perbuatan baik dan buruk. Nafsu dan jiwa harus dikendalikan agar jamaah dapat memperoleh ketenangan dan kedamaian dalam hidupnya. Pendalaman spiritual melalui ibadah yang dilakukan dalam rangka mendekatkan diri kepada Allah akan akan berdampak pada perubahan akhlak dan perilaku jamaah.
\end{abstract}

Kata Kunci : Gerak batin, transedental, interaksionisme simbolik

\begin{abstract}
Gerak Batin is one of the oldest muslimah jemaah in Pasuruan regency by NU. In the process, it has changed a main and purpose from the activity itself. This research used of descriptive qualitatif. The methode for collecting datas is structural interviewed. Heart, desire dan soul is one united that can not be seperated by each other. Heart covered desire that fulfill of struggle to do good and bad things. Desire and soul should be managed in order to get a piece and quitness for the jemaah's life. Enhanching spiritual through a worship that done to close with God (Allah) will be affected a change of jemaah's behavior and attitude.
\end{abstract}

Keywords : Gerak batin, transedental, symbolic interaction

\section{PENDAHULUAN}

Komunikasi adalah proses penyampaian pesan dari seorang komunikator kepada komunikan melalui sebuah media yang menghasilkan efek. Hubungan komunikasi yang dilakukan oleh manusia bisa dibagi menjadi dua jenis, yaitu hubungan horizontal (habluminannas) dan hubungan vertikal (habluminallah). Hubungan horizontal (habluminannas) terjadi antar manusia dengan manusia lainnya, sedangkan hubungan vertikal (habluminallah) terjadi antara manusia dengan Tuhannya. Komunikasi yang 
dilakukan atau terjadi antara manusia dengan Tuhannya itulah yang disebut Komunikasi Transedental.

Salah satu perwujudan dari komunikasi transedental yang ada di masyarakat adalah gerak batin yang ada di Desa Glagahsari Kecamatan Sukorejo. Awal mulanya, didirikannya gerak batin memiliki makna untuk memperkuat jalinan ukhuwah islamiah diantara muslimah yang ada di Desa Glagahsari. Selain itu, gerak batin merupakan sebuah bentuk ikhtiar dari para muslimah Glagahsari dalam ritual melalui doa khizib nashor agar desanya terhindar dari ancaman kejahatan yang dilakukan oleh para kelompok PKI Gestapu (Gerakan September Tiga Puluh). Seiring dengan perkembangan zaman, dengan berakhirnya zaman Gestapu, gerak batin tidak seketika itu juga ikut berakhir. Gerak batin tetap istiqomah berjalan, akan tetapi memiliki makna yang berbeda dalam ritualnya. Gerak batin bertransformasi menjadi sebuah jamaah pengajian yang memiliki tujuan menggerakkan batin (hati) untuk selalu mendekatkan diri kepada Allah SWT. Gerak batin juga merupakan salah satu pengajian muslimah tertua dalam naungan Nahdlatul Ulama (NU) Pasuruan yang dipimpin oleh seorang Muslimah. Padahal rata-rata jamaah pengajian di Kabupaten Pasuruan dipimpin oleh seorang laki-laki.

Berdasarkan fenomena yang terjadi, peneliti tertarik untuk melakukan penelitian mengenai ritual gerak batin sebagai komunikasi transedental, karena dengan adanya transformasi makna dan interaksi yang ada dalam gerak batin, jamaah tersebut dalam tetap istiqomah berjalan. Gerak batinpun merupakan salah satu pengajian tertua yang dipimpin oleh muslimah dibawah naungan NU, padahal rata-rata pemimpin pengajian di Kabupaten Pasuruan adalah seorang laki-laki. Oleh karena itu, peneliti mencoba mengangkatnya menjadi sebuah bentuk penelitian.

Tujuan penelitian ini sesuai dengan permasalahan yang diangkat, yaitu menganalisis komunikasi transedental jamaah gerak batin di desa Glagahsari dengan pendekatan simbolic interaction theory.

\section{KAJIAN TEORI}

\section{Komunikasi Transedental}


Menurut Nina W. Syam (2013, h.133), dalam khazanah ilmu komunikasi, komunikasi transedental merupakan salah satu bentuk komunikasi di samping komunikasi antarpersonal, komunikasi kelompok, komunikasi organisasi, komunikasi antar budaya, komunikasi verbal, komunikasi non verbal dan komunikasi massa. Namun komunikasi transedental tidak pernah dibahas luas. Cukup dikatakan bahwa komunikasi transedental adalah komunikasi antara manusia dengan Tuhan. Menurut Nina W. Syam (2015, h.107), alam perspektif psikologi sufi, komunikasi transedental terdiri dari 3 (tiga) konsep, yaitu :

\section{a. Konsep Hati}

Konsep hati yang dimaksud dalam psiklogi sufi adalah hakikat spiritual batiniah. Hati adalah sumber cahaya batiniah, inspirasi, kreativitas, dan belas kasih. Menurut Tirdmizi, hati kita memiliki empat stasiun, yakni dada, hati, hati lebih dalam, dan lubuk hati yang terdalam. Dada adalah lingkaran paling luar (kesatu) yang mewadahi cahaya amaliah dari betuk praktik agama. Lingkaran kedua, hati yang mewadahi cahaya iman, seperti telah didefinisikan, yaitu hati yang halus (Ihatifah) yang rabbaniyah dan ruhiyah yang merupakan rumah takwa. Lingkaran ketiga adalah hati yang lebih dalam (Fu'ad) yang merupakan tempat penglihatan cahaya batin dan inti dari makrifat (kearifan batin) atau pengetahuan hakikat spiritual. Lingkaran keempat adalah lubuk hati yang terdalam, dialiri oleh kemurahan Allah dan akhirnya dipadati dengan cahaya-cahaya kebenaran yang hakiki yang hanya didapatkan dari lubuk hati yang paling dalam.

b. Konsep Nafs

Menurut Robet yang dikuti dari Nina Winangsih Syam (2015, h.111), konsep nafs dalam psikologi sufi adalah sebuah aspek yang sangat buruk bagi diri manusia. Definisi nafs dalam bahasa arab adalah diri. Diri dalam pandangan sufi ini terdiri dari tingkatan-tingkatan yang diantaranya adalah nafs tirani, nafs penyesalan, nafs terilhami, nafs tenteram, nafs ridha, nafs diridhai dan nafs suci.

c. Konsep Jiwa

Menurut Nina Winangsih Syam (2015, h.118), jiwa menurut kaum sufi memiliki tujuh sisi, yakni jiwa hewani, mineral, nabati, pribadi, insani, rahasia, dan 
maharahasia. Tiap jiwa memiliki potensi. Dalam jiwa yang tidak seimbang akan memberikan efek negatif bagi perkembangan spiritual seseorang.

\section{Teori Interaksionisme Simbolik}

Beberapa orang ilmuwan punya andil utama sebagai perintis interaksionisme simbolik, diantaranya James Mark Baldin, William James, Charles H. Cooley, John Dewey, William I. Thomas, dan George Herbert Mead. Para ilmuwan pragmatis ini percaya bahwa realitas bersifat dinamis, dan ide ini bukan merupakan ide yang populer pada masa itu (West \& Turner, 2014, h. 97).

Orang tergerak untuk bertindak berdasarkan makna yang diberikannya pada orang, benda, dan peristiwa. Makna-makna ini diciptakan dalam bahasa yang digunakan orang baik untuk berkomunikasi dengan orang lain maupun dengan dirinya sendiri, atau pikiran pribadinya. Interaksi simbolik didasarkan pada ide-ide mengenai diri dan hubungannya dengan masyarakat. Menurut Ralph LaRossa dan Donald C. Reitzes (1993) yang dikutip dari West \& Turner (2014, h. 98), telah mempelajari Teori Interaksi Simbolik yang berhubungan dengan kajian menegenai keluarga. Mereka mengatakan bahwa tujuh asumsi mendasari Interaksi Simbolik dan bahwa asumsiasumsi ini memperlihatkan tiga tema besar yaitu :

\section{Pentingnya makna bagi perilaku manusia}

Teori interaksionisme simbolik berpegang bahwa individu membentuk makna melalui proses komunikasi karena makna tidak bersifat intrinsik terhadap apa pun. Dibutuhkan interpretif di antara orang-orang untuk menciptakan makna. Bahkan, tujuan dari interaksi, menurut interaksi simbolik, adalah untuk menciptakan makna yang sama.

2. Pentingnya konsep mengenai diri

Konsep diri adalah seperangkat persepsi yang relatif stabil yang dipercaya orang mengenai dirinya sendiri. Karakteristik yang diakui Roger (atau setiap actor sosial) tentang ciri-ciri fisiknya, peranan, talenta, keadaan emosi, nilai, keterampilan dan keterbatasan sosial, intelektualitas, dan seterusnya membentuk konsep dirinya. Pernyataan ini merupakan hal yang sangat penting untuk Interaksionisme Simbolik. Selanjutnya, Interaksi Simbolik sangat tertarik dengan cara orang mengembangkan 
konsep diri, Interaksi Simbolik menggambarkan individu dengan diri yang aktif, didasarkan pada interaksi sosial dengan orang lainnya.

3. Hubungan antar individu dengan masyarakat

Hubungan ini berkaitan dengan hubungan antara kebebasan individu dan masyarakat, dimana norma-norma sosial membatasi perilaku tiap individunya, tetapi pada akhirnya tiap individulah yang menentukan pilihan yang ada dalam sosial kemasyarakatannya. Mead dan Blumer mengambil posisi di tengah untuk pertanyaan ini. Mereka mencoba untuk menjelaskan baik mengenai keteraturan dan perubahan dalam proses sosial.

\section{METODE PENELITIAN}

\section{Jenis Penelitian}

Penelitian ini menggunakan jenis penelitian kualitatif deskriptif karena jenis penelitian ini bertujuan membuat deskripsi secara sistematis, faktual, dan akurat tentang fakta-fakta dan sifat-sifat populasi atau objek tertentu (Kriyantono, 2010, h.69). Penelitian deskriptif berusaha menemukan pola sederhana yang didasarkan pada konsep tertentu. Dengan demikian, seorang peneliti yang menggunakan penelitian deskriptif mengedepankan pentingnya konsep rujukan dalam mengukur suatu fenomena (Bajari, 2015, h.45).

\section{Fokus Penelitian}

Dalam penelitian ini, peneliti mengambil fokus penelitian tentang komunikasi transedental, karena komunikasi transedental adalah sesuatu yang sangat penting namun tidak banyak orang yang menggali dan mengerti secara lebih dalam. Dikatakan penting karena keberhasilan manusia melakukannya tidak saja menentukan nasibnya di dunia tetapi juga di akhirat. Karena komunikasi transedental adalah habluminallah, dan komunikasi yang lainnya adalah hablumminannas. Selain itu, peneliti mengambil fokus penelitian ini karena termasuk juga dalam disiplin ilmu komunikasi.

\section{Unit Analisis}

Adapun unit analisis dari penelitian ini adalah sebagai berikut :

A. Konsep hati

1. Dada (Shadr) 
Dada adalah lingkaran paling luar yang mewadahi cahaya amaliah yang diaplikasikan oleh jamaah gerak batin dalam melakukan kegiatan ibadah kepada Allah seperti sholat, puasa, zakat, dzikir, sholawat dan lain sebagainya.

2. Hati (Lhatifah)

Hati adalah lingkaran kedua yang mewadahi cahaya iman. Hal ini diaplikasikan oleh jamaah gerak batin melalui sikap takut mereka dalam berbuat keburukan atau dosa.

3. Hati lebih dalam (Fu'ad)

Hati lebih dalam adalah lingkaran ketiiga yang mewadahi cahaya batin. Hal ini jamaah gerak batin rasakan dari hatinya yang terasa sangat dekat dengan Allah.

4. Lubuk hati yang terdalam

Lubuk hati yang terdalam adalah lingkaran terdalam yang mewadahi cahaya kebenaran yang hakiki. Bagi jamaah gerak batin kebenaran hakiki didapat melalui penimbahan dan pendalaman ilmu agama yang diterapkan dalam kehidupannya.

B. Konsep Nafs

1. Nafs Tirani

Nafs tirani adalah kekuatan yang menjauhkan kita dalam meningkatkan spiritualitas. Untuk mengatasi nafs tirani, jamaah gerak batin dibekali dengan siraman rohani yang dilakukan rutin tiap bulan.

2. Nafs penyesalan

Nafs penyesalan adalah nafs yang menolak amalan buruk dan memohon ampun atas kesalahan yang disadari. Untuk meminimalisir nafs tersebut, jamaah diberikan tausyiah-tausyiah singkat setiap awal kegiatan rutinan.

3. Nafs Terilhami

Nafs terilhami adalah nafs yang didominasi oleh sifat kedermawanan, qonaah, tawakkal dan taubat. Untuk menyikapi nafs terilhami, jamaah gerak batin diberikan bimbingan serta pengawasan agar tidak lagi terjerumus kedalam keburukan. 
4. Nafs Tenteram

Nafs tenteram adalah nafs yang mencakup keyakinan terhadap Allah. Nafs tenteram hadir dengan adanya rasa cinta kepada Allah. Untuk menyikapinya, jamaah gerak batin selalu diberikan wejangan agar selalu bersyukur atas segala yang diberikan oleh Allah.

5. Nafs Ridha

Nafs ridha adalah nafs yang mana perhatian kita tidak lagi tertuju pada urusan duniawi, tetapi hanya fokus kepada Allah semata. Untuk menyikapinya, jamaah gerak batin diminta untuk neriman dan legowo apabila diberikan cobaan maupun kenikmatan.

6. Nafs Diridhai

Nafs diridhai adalah tingkatan pernikahan antara diri dan roh. Untuk menyikapinya, jamaah gerak batin diberikan pemahaman bahwa segala sesuatu baik ataupun buruk yang dialami adalah datangnya dari Allah.

7. Nafs Suci

Nafs suci adalah tidak ada lagi ego maupun diri, yang ada hanya kesatuan dengan Allah. Untuk menyikapi nafs suci, jamaah gerak batin diminta untuk selalu berserah diri kepada Allah.

C. Konsep Jiwa

1. Jiwa Mineral

Jiwa mineral meliputi perilaku yang terlalu kaku. Untuk mengatasi jiwa mineral, jamaah gerak batin diberikan siraman rohani yang dilakukan setiap malam Jum'at Legi.

2. Jiwa Nabati

Jiwa nabati meliputi perilaku kemalasan. Untuk meminimalisir jiwa nabati, jamaah diberikan motivasi baik melalui tausyiah maupun siraman rohani.

3. Jiwa Hewani

Jiwa hewani meliputi perilaku amarah, ketamakan dan suka akan kesenangan. Dalam mengatasi jiwa hewani, jamaah gerak batin diberikan air doa untuk melunakkan hatinya yang keras. 
4. Jiwa Pribadi

Jiwa pribadi meliputi perilaku egois dan memiliki ego yang lemah. Dalam mengoptimalkan jiwa pribadi, jamaah gerak batin dibiasakan untuk memberikan santunan kepada anak yatim.

5. Jiwa Insani

Jiwa insani meliputi perilaku sentimentalis. Dalam mengoptimalkan jiwa insani, jamaah dianjurkan untuk tidak ragu dalam bersedekah kepada sesama yang membutuhkan.

6. Jiwa Rahasia

Jiwa rahasia meliputi perilaku penolakan terhadap dunia. Untuk mengoptimalkan jiwa rahasia, jamaah gerak batin diberikan kesadaran bahwa ibadah memiliki 2 (dua) hubungan yaitu kepada Allah dan kepada manusia itu sendiri.

7. Jiwa Maharahasia

Dalam jiwa maharahasia tidak ada lagi perilaku negatif yang muncul karena jiwa inilah yang merupakan hakikat dari komunikasi transedental itu sendiri. Untuk mengoptimalkan jiwa maharahasia, jamaah gerak batin diminta untuk selalu istiqomah berada dalam jalan kebaikan yaitu agama Islam.

\section{Teknik Pengumpulan Data}

Teknik pengumpulan data yang digunakan dalam penelitian ini adalah wawancara. Menurut Berger dalam Kriyantono (2010, h.100) wawancara adalah percakapan antara peneliti (seseorang yang berharap mendapatkan informasi) dan informan (seseorang yang diasumsikan mempunyai informasi penting tentang suatu objek).

Dalam penelitian ini, peneliti menggunkan jenis wawancara terstruktur. Pada jenis wawancara ini, peneliti menggunakan pedoman wawancara, yang merupakan bentuk spesifik yang berisi intruksi yang mengarahkan peneliti dalam melakukan wawancara.

\section{Teknik Analisis Data}

Data yang telah peneliti peroleh akan dianalisis dengan model yang telah ditawarkan oleh Miles dan Huberman. Menurut Sugiyono (2012, h.246) aktifitas dalam 
analisis data yaitu : data reduction, data display, dan data conclusion drawing/verification.

1. Data Reduction (Reduksi Data)

Data yang diperoleh dari lapangan jumlahnya cukup banyak, untuk itu maka perlu dicatat secara teliti dan rinci. Untuk itu perlu segera dilakukan analisis data melalui reduksi data. Mereduksi data berarti merangkum, memilih hal-hal yang pokok, memfokuskan pada hal-hal yang penting, dicari tema dan polanya. Dengan demikian data yang telah direduksi akan memberikan gambaran yang lebih jelas, dan mempermudah peneliti untuk melalukan pengumpulan data selanjuttnya.

\section{Data Display (Penyajian Data)}

Setelah data direduksi, maka langkah selanjutnya adalah mendisplaykan data. Menyajikan data dilakukan dengan cara mengorganisasikan informasi yang sudah direduksi. Data tersebut mula-mula disajian terpisah, tetapi setelah tindakan terakhir direduksi, keseluruhan data tindakan dirangkum dan disajikan secara terpadu sehingga diperoleh sajian tunggal berdasarkan fokus pembelajaran membaca pemahaman dengan pendekatan teori interaksionisme simbolik.

\section{Verification (Penarikan Kesimpulan)}

Langkah ketiga adalah penarikan kesimpulan dan verifikasi. Kesimpulan awal yang dikemukakan masih bersifat sementara, dan akan berubah bila tidak ditemukan bukti-bukti yang kuat yang mendukung pada tahap pengumpulan data berikutnya. Tetapi apabila kesimpulan yang dikemukakan pada tahap awal, didukung oleh buktibukti yang valid dan konsisten saat peneliti kembali kelapangan mengumpulkan data, maka kesimpulan yang dikemukakan merupakan kesimpulan yangg kredibel.

\section{HASIL DAN PEMBAHASAN}

\section{Analisis Konsep Hati}

Hati adalah wadah dari pusat spiritualitas seorang jamaah. Karena hati adalah tempat bersemayam rasa cinta jamaah yang diaplikasikan melalui ibadah-ibadahnya kepada Allah. Sebagai tempat bersemayamnnya cinta kepada Allah, hati sudah sepatutnya untuk dituruti dan tidak tergoda atas panggilan nafsu yang mengarahkan diri untuk melakukan perbuatan yang dilarang oleh Allah. Hati yang telah dekat dengan 
Allah tentunya akan semakin merasakan rindu yang begitu dalam untuk selalu berkomunikasi dengan Allah melalui ibadahnya. Akan datang rasa khawatir ketika akan melakukan suatu perbuatan keburukan.

Berdasarkan Teori Interaksionisme Simbolik yang terbagi menjadi 3 (tiga) konsep, yaitu makna, konsep diri, dan hubungan masyarakat. Makna hati bagi jamaah gerak batin adalah tempat bersemayamnya kebenaran dalam diri jamaah. Yang mana dalam gerak batin sendiri memiliki tujuan untuk dapat menggerakkan hatinya agar selalu beribadah kepada Allah. Karena dengan hati yang telah tergerak, akan selalu timbul kerinduan untuk berkomunikasi kepada Allah.

Dengan pemahaman atas hati, konsep diri jamaah akan terbentuk dengan baik. Persepsi diri jamaah akan dipenuhi rasa kebaikan kepada sesama, berupa sifat lapang dada. Persepsi diri yang baik akan membawa kebaikan pula kepada jamaah ketika melakukan hubungan masyarakat dengan sesama manusia.

\section{Analisis Konsep Nafs}

Nafsu sering dipandang sebagai suatu hal yang buruk bagi manusia. Hal tersebut tentulah tidak benar, karena nafsu memiliki tingkatan-tingkatan tersendiri. Tugas dari jamaah adalah bagaimana cara mereka dalam meminimalisir dan mengendalikan nafsu mereka agar membawa kebaikan kepada dirinya. Nafsu akan semakin mudah dikendalikan ketika seorang jamaah memiliki pengetahuan spiritual yang tinggi. Karena ilmu merupakan kunci dari pengendalian nafsu itu sendiri. Dengan ilmu, seorang jamaah akan mudah melihat manakah perbuatan baik dan manakah perbuatan buruk. Nafsu yang timbul akan lebih mudah untuk dikekang olehnya.

Berdasarkan Teori Interaksionisme Simbolik yang terbagi menjadi 3 (tiga) konsep, yaitu makna, konsep diri, dan hubungan masyarakat. Jamaah gerak batin memaknai nafsu sebagai suatu hal yang wajib dikurung dengan jalan taubat. Karena nafsu selalu menghantui diri jamaah, maka perlu sebuah kontinuitas dalam melakukan pengendalian nafsu. Hal ini tercermin dengan kegiatan siraman rohani dan tausyiah yang dilakukan secara rutin pada jamaah gerak batin. Dengan adanya dakwah-dakwah yang menyejukkan hati, diharapkan akan dapat membelenggu nafsu itu sendiri.

Nafsu yang telah dikendalikan, akan membawa jamaah untuk memiliki konsep diri yang sabar, tidak mudah terprovokasi dan bijak dalam mengatasi suatu persoalan. Hal 
ini akan menyebabkan dirinya dipandang baik serta memiliki kebijaksanaan di tengah hidup bermasyarakat.

Hubungan dengan sesama manusia akan menjadi baik jika nafsu telah bisa dikendalikan. Hal ini akan menimbulkan sebuah bentuk kerukunan dalam kehidupan bermasyarakat. Jamaah yang mulanya pemarah akan menjadi lebih santun dan lebih bijaksana ketika melakukan interaksi. Tentunya hal ini akan menjadi kesenangan tersendiri bagi orang yang berinteraksi dengannya. Adanya rasa nyaman dan tenang saat berinteraksi, membuat orang lain tidak akan segan untuk sering melakukan obrolan bahkan terkait persoalan pribadinya.

\section{Analisis Konsep Jiwa}

Jiwa memiliki perilaku yang mendorong kita dalam melakukan keburukan dan kebaikan. Masing-masing tingkatan jiwa memiliki sisi positif dan negatifnya. Maka dari itu, sisi negatif jiwa haruslah ditekan dan diminimalisir agar kondisi dalam jiwa bisa berjalan seimbang. Tentu tidak mudah bagi jamaah untuk dapat mengatasi sisi negatifnya. Karena hal tersebut tentunya membutuhkan pengetahuan spiritual yang mendalam dan bimbingan dari orang lain agar tidak mudah terjerumus kembali kepada perilaku yang buruk

Untuk mencapai jiwa yang memiliki keseimbangan antara baik dan buruk, tentu dibutuhkan sebuah latihan keseimbangan jiwa. Hal ini dilakukan melalui ibadahibadah yang dilakukan secara rutin oleh jamaah, karena salah satu makna dari ibadah adalah untuk membentuk jiwa manusia itu sendiri agar memiliki jiwa yang berorientasi pada kebenaran dan kebajikan.

Berdasarkan Teori Interaksionisme Simbolik yang terbagi menjadi 3 (tiga) konsep, yaitu makna, konsep diri, dan hubungan masyarakat. Makna jiwa bagi jamaah gerak batin berarti keseimbangan, yakni menyeimbangkan setiap sisi dalam jiwa agar lebih optimal sisi kebaikannya. Menuju keseimbangan jiwa tersebut dilakukan dengan memupuk jiwa dengan pengetahuan spiritual yang didapat dari kegiatan siraman rohani. Hal ini bertujuan agar jiwa jamaah selalu ingat akan betapa besar kekuasaan dan keagungan Allah sehingga dapat menjadi pemicu bagi jamaah untuk meningkatkan kadar keimanan dan ketaqwaannya. 
Dengan jiwa yang dominan diisi dengan kebaikan tentu akan membentuk konsep diri yang baik pula bagi jamaah. Jiwa yang dipenuhi rasa belas kasih dan murah hati kepada sesama tentunya akan berimbas langsung pada perubahan kehidupan jamaah tersebut. Begitu pula dengan perubahan yang terjadi dengan hubungan masyarakatnya. Sebuah keharmonisan hubungan akan tercipta, dan menimbulkan kedamaian bagi diri sendiri maupun orang lain.

\section{PENUTUP}

\section{Kesimpulan}

Berdasarkan hasil analisis, diperoleh kesimpulan bahwa komunikasi transedental jamaah gerak batin berada dalam 3 (tiga) konsep, yaitu hati, nafsu dan jiwa. Hati, nafsu dan jiwa merupakan satu kesatuan dalam komunikasi transedental yang tidak dapat saling dipisahkan. Hati merupakan wadah bagi nafsu dan jiwa. Nafsu dan jiwa berisikan dorongan-dorongan untuk melakukan kebaikan maupun keburukan. Agar diri manusia selalu dipenuhi ketenangan dan kedamaian, maka perlu dilakukan sebuah pengendalian atas dorongan yang mengarah kepada keburukan. Pengendalian tersebut dilakukan dengan memperdalam pengetahuan spiritual jamaah dan kegiatan ibadah lainnya kepada Allah. Hal ini dilakukan semata-mata agar bisa mendekatkan diri kepada Allah. Dengan dekatnya diri manusia kepada Allah akan berimbas pada perubahan dirinya yang memiliki ketenangan dan kedamaian dalam hidupnya.

\section{Saran}

Berdasarkan kesimpulan yang telah dipaparkan diatas, peneliti memberikan saran bahwa dalam jamaah gerak batin perlu adanya peningkatan dalam kegiatan spiritual. Hal ini karena sisi negatif dari nafsu dan jiwa bukanlah hal yang mudah untuk diminimalisir dan dikendalikan. Oleh karenanya, perlu kegiatan spiritual lainnya yang lebih berfokus agar nafsu dan jiwa jamaah dapat dikendalikan dengan baik. 


\section{DAFTAR PUSTAKA}

Ainiyah, Nur \& Fajri. Moch. Isfironi. 2016. Komunikasi Transedental : Nalar Spiritual Interaksi Manusia dengan Tuhan (Perspektif Sufi). Jurnal Akhlak dan Tasawuf, Volume 2 Nomor 2.

Bajari, Atwar. 2015. Metode Penelitian Komunikasi Prosedur, Tren, dan Etika. Bandung : PT. Remaja Rosdakarya

Bungin, Burhan. 2017. Penelitian Kualitatif. Edisi Kedua. Jakarta : PT. Kharisma Putra Utama

Cartono, 2018. Komunikasi Islam dan Interaksi Media Sosial. Jurnal Dakwah dan Komunikasi, Volume 9 Nomor 2

Hardin. 2016. Komunikasi Transedental Dalam Ritual Kapontasu Pada Sistem Perladangan Masyarakat Etnik Muna. Jurnal Penelitian Komunikasi dan Opini Publik, Volume 20 Nomor 1

Hefni, Harjani. 2017. Komunikasi Islam. Jakarta : Kencana

Kumata, Olivia Dwi dkk. 2017. Efektivitas Pelatihan Dzikir Dalam Meningkatkan Ketenangan Jiwa pada Lansia Penderita Hipertensi. Jurnal Ilmiah Psikologi, Volume 4 Nomor 1.

Moleong, Lexy J. 2018. Metodologi Penelitian Kualitatif.. Bandung : Remaja Rosdakarya.

Mustofa, Agus. 2011. Energi Dzikir Alam Bawah Sadar. Jakarta : Padma Press

Nurhikmah. 2018. Komunikasi Transedental. Jurnal STAIN Pare-Pare.

Soleh, Harmarthilda. 2016. Doa dan Dzikir Dalam Meningkatkan Kecerdasan Emosi. Jurnal Psikologi Islami, Volume 2 Nomor 1

Sugiyono. 2012. Metode Penelitian Kuantitatif Kualitatif dan $R \&$ D. Bandung : Alfabeta

Suryani, Wahidah. 2015. Komunikasi Transedental Manusia-Tuhan. Jurnal Farabi, Volume 12 Nomor

Syam, Nina Winangsih. 2015. Komunikasi Transedental Prespektif Sains Terpadu. Bandung : Remaja Rosdakarya.

West, Richard \& Turner, Lynn H. 2014. Pengantar Teori Komunikasi Analisis dan Aplikasi. Edisi Ketiga. Jakarta : Salemba Humanika.

Yuwita, Nurma. 2017. Pluralisme Agama Dalam Kontruksi Pemikiran Pesantren Dengan Pendekatan Teori Interaksionisme Simbolik 